\title{
Solusi Sistem Persamaan Linear Fuzzy
}

\author{
${ }^{1}$ Irmawati, ${ }^{2}$ Icih Sukarsih, ${ }^{3}$ Respitawulan \\ ${ }^{1,2,3}$ Program Studi Matematika Fakultas Matematika dan Ilmu Pengetahuan Alam, Universitas Islam \\ Bandung, Jl. Tamansari No.01 Bandung 20116 \\ Email: ${ }^{1}$ wati_irma9394@yahoo.com, ${ }^{2}$ sukarsh@yahoo.co.id, ${ }^{3}$ respitawulan@gmail.com
}

\begin{abstract}
Let $\mathrm{A} \widetilde{U}=\tilde{V}$, with A is $n \times n$ real coefficient matrix which is real numbers, $\widetilde{U}$ is vector of $n$ unknown fuzzy variables, and $\tilde{V}$ is $n$ fuzzy constants vector. This system is named fuzzy linear equations system. To find the solution of fuzzy linear equations system $\mathrm{A} \widetilde{U}=\tilde{V}$, this system must be transformed into $B U^{*}=V^{*}$ with $B$ is $2 n \times 2 n$ coefficient matrix, $U^{*}$ is $2 n \times 1$ matrix of unknown variable, and $V^{*}$ is $2 n \times 1$ matrix of constants. The solution of $B U^{*}=V^{*}$ indirectly is the solution of $\mathrm{A} \widetilde{U}=\tilde{V}$, because the matrix $\widetilde{U}$ corresponded to $U^{*}$ is not necessarily fuzzy numbers. The necessary and sufficient condition to make the matrix $\widetilde{U}$ become the solution of $\mathrm{A} \widetilde{U}=\widetilde{V}$ is $B^{-1}$ must be non negative. To help finding the solution fuzzy linear equations system, on algorithm is built and implemented on Matlab.
\end{abstract}

Keywords: Fuzzy Linear Equations System, Fuzzy Numbers, Algorithm.

\begin{abstract}
Abstrak. Diberikan $\mathrm{A} \widetilde{U}=\tilde{V}$ dengan $A$ adalah matriks koefisien berukuran $n \times n$ yang merupakan bilangan real, $\widetilde{U}$ adalah $n$ variabel fuzzy yang tidak diketahui, $\widetilde{V}$ adalah vektor konstanta fuzzy dengan panjang $n$. Sistem tersebut dinamakan sistem persamaan linear fuzzy. Dalam mencari solusi sistem persamaan linear fuzzy A $\widetilde{U}=\tilde{V}$, sistem tersebut harus ditransformasikan dalam bentuk $B U^{*}=V^{*}$ dengan $B$ adalah matriks koefisien berukuran $2 n \times 2 n, U^{*}$ adalah matriks $2 n \times 1$ dari variabel yang tidak diketahui, dan $V^{*}$ adalah matriks $2 n \times 1$ dari konstanta. Solusi dari $B U^{*}=V^{*}$ tidak langsung menjadi solusi A $\widetilde{U}=\tilde{V}$, karena $\widetilde{U}$ yang bersesuaian dengan $U^{*}$ belum tentu berupa bilangan fuzzy. Syarat perlu dan cukup agar $\widetilde{U}$ merupakan solusi A $\widetilde{U}=\tilde{V}$, yaitu $B^{-1}$ harus non negatif. Untuk memudahkan mencari solusi dari sistem persamaan linear fuzzy perlu dibangun algoritma solusi sistem persamaan linear fuzzy dan implementasinya menggunakan Matlab.
\end{abstract}

Kata Kunci : Sistem Persamaan Linear Fuzzy, Bilangan Fuzzy, Algoritma.

\section{Pendahuluan}

Salah satu permasalahan yang sering dihadapi dalam bidang matematika adalah persoalan untuk mencari penyelesaian (solution) dari suatu sistem persamaan linear. Sistem persamaan linear ditemukan hampir di semua cabang ilmu pengetahuan, dan sistem-sistem linear muncul dalam penerapan bidang-bidang seperti perdagangan, ekonomi, sosiologi, elektronika, teknik, fisika, dan banyak lagi bidang lain.

Sistem persamaan linear yang biasanya dipelajari adalah koefisien, variabel dan konstantanya merupakan bilangan real, tetapi dalam dunia nyata tidak semua koefisien, variabel dan konstantanya harus real. Terdapat kasus-kasus tertentu yang koefisien, variabel dan konstantanya tidak menggunakan bilangan real, seperti bidang teori kontrol, teori keputusan, dan beberapa bagian dalam managemen sains. Bidangbidang tersebut memerlukan sistem persamaan yang berbasis teori fuzzy sebagai model matematikanya.

Sistem persamaan linear fuzzy dengan $n$ persamaan dan $n$ variabel yang tidak diketahui dapat ditulis dalam bentuk matriks $A \widetilde{U}=\widetilde{V}$. Penyelesaian sistem persamaan linear fuzzy dapat dilakukan dengan mentransformasikan sistem persamaan linear fuzzy $A \widetilde{U}=\tilde{V}$ ke dalam sistem persamaan linear non-fuzzy $B U^{*}=V^{*}$, dimana semua 
koefisien, variabel dan konstanta merupakan bilangan real. Solusi dari suatu sistem persamaan linear yang terbentuk, belum tentu merupakan solusi dari sistem persamaan linear fuzzy $A \widetilde{U}=\tilde{V}$. Ada syarat perlu dan cukup agar vektor $\widetilde{U}$ yang bersesuaian dengan $U^{*}$, sebagai solusi sistem persamaan linear $B U^{*}=V^{*}$ menjadi solusi dari sistem persamaan linear fuzzy. Untuk mempermudah mencari solusi dari sistem persamaan linear fuzzy perlu dibangun algoritma dan implementasinya menggunakan Matlab.

\section{Landasan Teori}

\section{Bilangan Fuzzy}

Menurut Goetchel \& Kaleva dalam Allahviranloo (2008) bilangan fuzzy dapat didefinisikan sebagai berikut :

\section{Definisi 1 (Bilangan Fuzzy)}

Sebuah bilangan fuzzy $u \in \mathbb{R}$ didefinisikan sebagai pasangan fungsi $(\underline{u}(r), \bar{u}(r))$, untuk $0 \leq r \leq 1$ yang memenuhi persyaratan sebagai berikut :

a. $\underline{u}(r)$ monoton naik dan fungsi kontinu kiri.

b. $\overline{\bar{u}}(r)$ monoton turun dan fungsi kontinu kanan.

c. $\underline{u}(r) \leq \bar{u}(r)$ untuk setiap $r$ dalam $[0,1]$.

Himpunan bilangan- bilangan fuzzy dinyatakan dengan $F$.

Bilangan fuzzy yang digunakan adalah bilangan fuzzy segitiga $\tilde{u}=(a, c, b)$ dengan fungsi keanggotaannya :

$$
\mu(x)=\left\{\begin{array}{lc}
\frac{x-a}{c-a}, & x \leq a \text { atau } x \geq b \\
\frac{x-b}{c-b}, & c \leq x \leq c
\end{array}\right.
$$

dengan $c \neq a, c \neq b$ untuk bilangan segitiga didapat $\underline{u}(r)=a+(c-a) r$ dan $\bar{u}(r)=b+(c-b) r$.

\section{Definisi 2 (Operasi pada bilangan fuzzy)}

Untuk sebarang $\tilde{u}=(\underline{u}(r), \bar{u}(r)), \tilde{v}=(\underline{v}(r), \bar{v}(r))$ dan $k>0$. Operasi yang ada pada bilangan fuzzy antara lain penjumlahan $\tilde{u}+\tilde{v}$, pengurangan $\tilde{u}-\tilde{v}$, perkalian $\tilde{u} . \tilde{v}$ dan perkalian skalar oleh $k$ sebagai berikut :

1. Penjumlahan

2. Pengurangan

$$
\underline{u-v}(r)=\underline{u}(r)-\underline{v}(r), \overline{u-v}(r)=\bar{u}(r)-\bar{v}(r)
$$

3. Perkalian

$$
\left\{\begin{array}{l}
\underline{u v}(r)=\min \{\underline{u}(r) \underline{v}(r), \underline{u}(r) \bar{v}(r), \bar{u}(r) \underline{v}(r), \bar{u}(r) \bar{v}(r)\} \\
\overline{u v}(r)=\max \{\underline{u}(r) \underline{v}(r), \underline{u}(r) \bar{v}(r), \bar{u}(r) \underline{v}(r), \bar{u}(r) \bar{v}(r)\}
\end{array}\right.
$$

4. Perkalian Skalar

$$
u=\left\{\begin{array}{l}
(k \underline{u}(r), k \bar{u}(r)), k \geq 0 \\
(k \bar{u}(r), k \underline{u}(r)), k<0
\end{array}\right.
$$

\section{Solusi Fuzzy dan Algoritma Pencarian Solusi}

Sistem persamaan linear fuzzy dengan $n$ persamaan dan $n$ variabel yang tidak diketahui memiliki bentuk : 


$$
\left\{\begin{array}{l}
a_{11} \tilde{u}_{1}+a_{12} \tilde{u}_{2}+\cdots+a_{1 n} \tilde{u}_{n}=\tilde{v}_{1} \\
a_{21} \tilde{u}_{1}+a_{22} \tilde{u}_{2}+\cdots+a_{2 n} \tilde{u}_{n}=\tilde{v}_{2} \\
\vdots \\
a_{n 1} \tilde{u}_{1}+a_{n 2} \tilde{u}_{2}+\cdots+a_{n n} \tilde{u}_{n}=\tilde{v}_{n}
\end{array}\right.
$$

dengan unsur-unsur $a_{i, j}$ yang merupakan bilangan real, unsur-unsur $\tilde{v}_{i}$ dari vektor konstanta dan $\tilde{u}_{j}$ berupa entri-entri dari variabel yang tidak diketahui, untuk $\tilde{v}_{i}, \tilde{u}_{j}$ merupakan bilangan fuzzy dan $1 \leq i, j \leq n$.

Sistem persamaan linear fuzzy dari persamaan (5) dapat dinyatakan dalam bentuk matriks sebagai berikut:

$$
\operatorname{dengan} A=\left[\begin{array}{cccc}
a_{11} & a_{12} & \ldots & a_{1 n} \\
a_{21} & a_{22} & \ldots & a_{2 n} \\
\vdots & \vdots & \ddots & \vdots \\
a_{n 1} & a_{n 2} & \cdots & a_{n n}
\end{array}\right], \widetilde{U}=\left[\begin{array}{c}
\tilde{u}_{1} \\
\tilde{u}_{2} \\
\vdots \\
\tilde{u}_{n}
\end{array}\right] \text { dan } \quad \tilde{V}=\left[\begin{array}{c}
\tilde{v}_{1} \\
\tilde{v}_{2} \\
\vdots \\
\tilde{v}_{n}
\end{array}\right] .
$$

Suatu model sistem persamaan linear (6) mempunyai solusi fuzzy jika terdapat vektor bilangan fuzzy $\widetilde{U}=\left(\tilde{u}_{1}, \tilde{u}_{2}, \ldots, \tilde{u}_{n}\right)^{t}$ dengan $\tilde{u}_{j}=\left(\underline{u_{j}}(r), \overline{u_{j}}(r)\right)$, untuk $1 \leq j \leq$ $n$ dan $0 \leq r \leq 1$ yang memenuhi :

$$
\underline{\sum_{i=1}^{n} a_{i j} u_{j}}=\sum_{i=1}^{n} a_{i j} u_{j}=\underline{v_{i}} \text { dan } \overline{\sum_{i=1}^{n} a_{i j} u_{j}}=\sum_{i=1}^{n} \overline{a_{i j} u_{j}}=\overline{v_{i}}
$$

Langkah awal untuk mencari penyelesaian dari sistem persamaan linear fuzzy (6) adalah dengan mengubah sistem persamaan linear fuzzy (6) menjadi sistem persamaan linear non-fuzzy. Sistem persamaan linear fuzzy (6) bentuknya berubah dari sistem $n$ variabel dan $n$ persamaan menjadi $2 n$ variabel dan $2 n$ persamaan :

$$
B U^{*}=V^{*}
$$

dengan

$$
B=\left[\begin{array}{cccc}
b_{11} & b_{12} & \cdots & b_{12 n} \\
b_{21} & b_{22} & \cdots & b_{22 n} \\
\vdots & \vdots & \ddots & \vdots \\
b_{2 n 1} & b_{2 n 2} & \cdots & b_{2 n 2 n}
\end{array}\right], U^{*}=\left[\begin{array}{c}
u_{1}{ }^{*} \\
u_{2}{ }^{*} \\
\vdots \\
u_{n}{ }^{*} \\
u_{n+1}{ }^{*} \\
u_{n+2}{ }^{*} \\
\vdots \\
u_{2 n}{ }^{*}
\end{array}\right]=\left[\begin{array}{c}
\underline{u}_{1} \\
\underline{u}_{2} \\
\vdots \\
\underline{u}_{n} \\
-\bar{u}_{1} \\
-\bar{u}_{2} \\
\vdots \\
-\bar{u}_{n}
\end{array}\right], V^{*}=\left[\begin{array}{c}
v_{1}{ }^{*} \\
v_{2}{ }^{*} \\
\vdots \\
v_{n}{ }^{*} \\
v_{n+1}{ }^{*} \\
v_{n+2}{ }^{*} \\
\vdots \\
v_{2 n}{ }^{*}
\end{array}\right]=\left[\begin{array}{c}
\underline{v}_{1} \\
\underline{v}_{2} \\
\vdots \\
\underline{v}_{n} \\
-\bar{v}_{1} \\
-\bar{v}_{2} \\
\vdots \\
-\bar{v}_{n}
\end{array}\right] .
$$

dengan entri-entri $b_{i, j}$ ditentukan sebagai berikut :

1. jika $a_{i j} \geq 0$ maka $b_{i j}=a_{i j} \operatorname{dan} b_{i+n j+n}=a_{i j}$

2. jika $a_{i j}<0$ maka $b_{i j+n}=-a_{i j}$ dan $b_{i+n}=-a_{i j}$

3. $b_{i j}=0$ untuk lainnya.

Persamaan (7) bukan lagi sistem persamaan linear fuzzy, karena semua entrientrinya bukan bilangan fuzzy. Persamaan (7) merupakan persamaan linear yang nilai variabelnya berada dalam ruang fungsi. Dengan menggunakan persamaan (7), sistem persamaan linear fuzzy dapat diselesaikan melalui penyelesaian sistem persamaan linear. Sistem persamaan linear (7) mempunyai solusi jika dan hanya matriks $B$ nonsingular (Anton,1987). Matrik $B$ nonsingular jika dan hanya jika $\operatorname{det}(B) \neq 0$. Jika $U^{*}$ adalah solusi dari sistem persamaan linear (7), maka solusi dari sistem persamaan linear fuzzy (6) dapat dibentuk sebagai berikut : 


$$
\widetilde{U}=\left[\begin{array}{c}
\tilde{u}_{1} \\
\tilde{u}_{2} \\
\vdots \\
\tilde{u}_{n}
\end{array}\right]=\left[\begin{array}{c}
\left(\underline{u}_{1}, \bar{u}_{1}\right) \\
\left(\underline{u}_{2}, \bar{u}_{2}\right) \\
\vdots \\
\left(\underline{u}_{n}, \bar{u}_{n}\right)
\end{array}\right]=\left[\begin{array}{c}
\left(u_{1}{ }^{*},-u_{n+1}{ }^{*}\right) \\
\left(u_{2}{ }^{*},-u_{n+2}{ }^{*}\right) \\
\vdots \\
\left(u_{n}{ }^{*},-u_{2 n}{ }^{*}\right)
\end{array}\right]
$$

Setelah dibentuk vektor $\widetilde{U}$, vektor tersebut dicek apakah merupakan bilangan fuzzy atau bukan. Jika vektor $\widetilde{U}=\left[\tilde{u}_{1}, \tilde{u}_{2}, \cdots, \tilde{u}_{n}\right]^{t}$ merupakan bilangan fuzzy, maka vektor $\widetilde{U}=\left[\tilde{u}_{1}, \tilde{u}_{2}, \cdots, \tilde{u}_{n}\right]^{t}$ merupakan solusi dari sistem persamaan linear fuzzy (6). Sebaliknya, jika vektor $\widetilde{U}=\left[\tilde{u}_{1}, \tilde{u}_{2}, \cdots, \tilde{u}_{n}\right]^{t}$ bukan merupakan bilangan fuzzy, maka vektor $\widetilde{U}=\left[\tilde{u}_{1}, \tilde{u}_{2}, \cdots, \tilde{u}_{n}\right]^{t}$ bukan merupakan solusi dari sistem persamaan linear fuzzy (6).

Contoh 1. Diberikan sistem persamaan linear fuzzy :

$$
\begin{array}{cc}
\tilde{u}_{1}+2 \tilde{u}_{3} & =(r-2,-r) \\
-3 \tilde{u}_{1}+4 \tilde{u}_{2}+6 \tilde{u}_{3} & =(r-3,-r+1) \\
-\tilde{u}_{1}-2 \tilde{u}_{2}+3 \tilde{u}_{3}=(2 r+1,-r+4)
\end{array}
$$

Dibentuk matriks $B U^{*}=V^{*}$ sesuai dengan persamaan (7), didapat :

$$
B=\left[\begin{array}{cccccc}
1 & 0 & 2 & 0 & 0 & 0 \\
0 & 4 & 6 & 3 & 0 & 0 \\
0 & 0 & 3 & 1 & 2 & 0 \\
0 & 0 & 0 & 1 & 0 & 2 \\
3 & 0 & 0 & 0 & 4 & 6 \\
1 & 2 & 0 & 0 & 0 & 3
\end{array}\right], U^{*}=\left[\begin{array}{l}
u_{1}^{*} \\
u_{2}{ }^{*} \\
u_{3}{ }^{*} \\
u_{4}{ }^{*} \\
u_{5}{ }^{*} \\
u_{6}{ }^{*}
\end{array}\right]=\left[\begin{array}{c}
\underline{u}_{1} \\
\underline{u}_{2} \\
\underline{u}_{3} \\
-\bar{u}_{1} \\
-\bar{u}_{2} \\
-\bar{u}_{3}
\end{array}\right] \text { dan } V^{*}=\left[\begin{array}{c}
r-2 \\
r-3 \\
2 r+1 \\
r \\
r-1 \\
r-4
\end{array}\right] .
$$

karena determinan dari matriks $B$ tidak sama dengan nol, maka sistem $\mathrm{BU}^{*}=$ $\mathrm{V}^{*}$ mempunyai solusi dan solusinya adalah

$$
U^{*}=\left[\begin{array}{l}
u_{1}{ }^{*} \\
u_{2}{ }^{*} \\
u_{3}{ }^{*} \\
u_{4}{ }^{*} \\
u_{5}{ }^{*} \\
u_{6}{ }^{*}
\end{array}\right]=\left[\begin{array}{c}
\underline{u}_{1} \\
\underline{u}_{2} \\
\underline{u}_{3} \\
-\bar{u}_{1} \\
-\bar{u}_{2} \\
-\bar{u}_{3}
\end{array}\right]=\left[\begin{array}{c}
-2.0909 \mathrm{r}+0.0909 \\
-0.6364 r-0.6136 \\
1.5455 r-1.0455 \\
-1.9091 \mathrm{r}+1.9091 \\
-0.3636 \mathrm{r}+1.1136 \\
1.4545 r-0.9545
\end{array}\right]
$$

Karena vektor $\widetilde{U}=\left[\tilde{u}_{1}, \tilde{u}_{2}, \tilde{u}_{3}\right]^{t}$ tidak memenuhi Definisi 1 maka vektor $\widetilde{U}=\left[\tilde{u}_{1}, \tilde{u}_{2}, \tilde{u}_{3}\right]^{t}$ bukan merupakan bilangan fuzzy. Jadi vektor $\widetilde{U}=\left[\tilde{u}_{1}, \tilde{u}_{2}, \tilde{u}_{3}\right]^{t}$ bukan merupakan solusi dari sistem persamaan linear fuzzy contoh 1.

Contoh 2. Diberikan sistem persamaan linear fuzzy :

$$
\begin{gathered}
-4 \tilde{u}_{1}=(r-3,-r) \\
-\tilde{u}_{2}=(-4+r,-r-1)
\end{gathered}
$$

Dibentuk matriks $B U^{*}=V^{*}$ sesuai dengan persamaan (7), didapat :

$$
B=\left[\begin{array}{llll}
0 & 0 & 4 & 0 \\
0 & 0 & 0 & 1 \\
4 & 0 & 0 & 0 \\
0 & 1 & 0 & 0
\end{array}\right], U^{*}=\left[\begin{array}{l}
u_{1}{ }^{*} \\
u_{2}{ }^{*} \\
u_{3}{ }^{*} \\
u_{4}{ }^{*}
\end{array}\right]=\left[\begin{array}{c}
\underline{u}_{1} \\
\underline{u}_{2} \\
-\bar{u}_{1} \\
-\bar{u}_{2}
\end{array}\right], V^{*}=\left[\begin{array}{c}
r-3 \\
-4+r \\
r \\
r+1
\end{array}\right]
$$

karena determinannya tidak sama dengan nol, maka sistem $B U^{*}=$ $V^{*}$ mempunyai solusi sebagai berikut :

$$
U^{*}=\left[\begin{array}{l}
u_{1}{ }^{*} \\
u_{2}{ }^{*} \\
u_{3}{ }^{*} \\
u_{4}{ }^{*}
\end{array}\right]=\left[\begin{array}{c}
\underline{u}_{1} \\
\underline{u}_{2} \\
-\bar{u}_{1} \\
-\bar{u}_{2}
\end{array}\right]=\left[\begin{array}{c}
0,25 r \\
r+1 \\
0,25 r-0,75 \\
r-4
\end{array}\right]
$$


Karena vektor $\widetilde{U}=\left(\tilde{u}_{1}, \tilde{u}_{2}\right)$ memenuhi Definisi 1 , maka vektor $\widetilde{U}=\left[\tilde{u}_{1}, \tilde{u}_{2}\right]^{t}$ merupakan bilangan fuzzy. Jadi vektor $\widetilde{U}=\left[\tilde{u}_{1}, \tilde{u}_{2}\right]^{t}$ merupakan solusi dari sistem persamaan linear fuzzy contoh 2.

Contoh 3. Diberikan sistem persamaan linear fuzzy:

$$
\begin{array}{cc}
\tilde{u}_{1}+2 \tilde{u}_{2}+2 \tilde{u}_{3} & =(r-4,-2 r) \\
-\tilde{u}_{1}-5 \tilde{u}_{2}+9 \tilde{u}_{3} & =(-3+r,-4-r) \\
2 \tilde{u}_{1}+4 \tilde{u}_{2}+8 \tilde{u}_{3} & =(r-1,2-r)
\end{array}
$$

Dibentuk matriks $B U^{*}=V^{*}$ sesuai dengan persamaan (7) didapat :

$$
B=\left[\begin{array}{cccccc}
1 & 2 & 4 & 0 & 0 & 0 \\
0 & 0 & 9 & 1 & 5 & 0 \\
2 & 4 & 8 & 0 & 0 & 0 \\
0 & 0 & 0 & 1 & 2 & 4 \\
1 & 5 & 0 & 0 & 0 & 9 \\
0 & 0 & 0 & 2 & 4 & 8
\end{array}\right], U^{*}=\left[\begin{array}{l}
u_{1}{ }^{*} \\
u_{2}{ }^{*} \\
u_{3}{ }^{*} \\
u_{4}{ }^{*} \\
u_{5}{ }^{*} \\
u_{6}{ }^{*}
\end{array}\right]=\left[\begin{array}{c}
\underline{u}_{1} \\
\underline{u}_{2} \\
\underline{u}_{3} \\
-\bar{u}_{1} \\
-\bar{u}_{2} \\
-\bar{u}_{3}
\end{array}\right] \text {, dan } V^{*}=\left[\begin{array}{c}
r-4 \\
-3+r \\
r-1 \\
2 r \\
4+r \\
r-2
\end{array}\right]
$$

karena determinannya sama dengan nol, maka sistem $B U^{*}=V^{*}$ tidak mempunyai solusi.

Walaupun sistem persamaan $B U^{*}=V^{*}$ pada contoh 1 dan contoh 2 mempunyai solusi tunggal, tidak berarti $\widetilde{U}$ yang bersesuaian dengan $U^{*}$ merupakan solusi dari persamaan linear fuzzy contoh 1 dan contoh.2. Jika $B$ dalam contoh 1 dan 2 nonsingular, tidak ada jaminan bahwa $\widetilde{U}$ yang bersesuaian dengan $U^{*}$ merupakan bilangan fuzzy untuk setiap $V^{*} \in F$. Ada syarat perlu dan cukup agar sistem persamaan linear fuzzy punya solusi.

Teorema 1 : Misalkan $B=\left[\begin{array}{ll}B_{1} & B_{2} \\ B_{2} & B_{1}\end{array}\right]$ adalah matriks koefesien pada persamaan (7). Matriks $\mathrm{B}$ nonsingular jika dan hanya jika matriks-matriks $A=$ $B_{1}-B_{2}$ dan $B_{1}+B_{2}$ keduanya nonsingular.

Teorema 2 : Misalkan $B=\left[\begin{array}{ll}B_{1} & B_{2} \\ B_{2} & B_{1}\end{array}\right]$ adalah matriks koefesien pada persamaan (7). Jika invers matriks $B$ ada, maka inversnya berbentuk $B^{-1}=$ $\left[\begin{array}{ll}M & N \\ N & M\end{array}\right]$

Toerema 3 :Misalkan sistem persamaan linear fuzzy A $\widetilde{U}=\widetilde{V}$ dengan $n$ variabel dan $n$ persamaan. Persamaan $B U^{*}=V^{*}$ seperti persamaan (7), dengan $B$ nonsingular. Vektor $\widetilde{U}$ yang bersesuaian dengan $U^{*}$ yang merupakan solusi $B U^{*}=V^{*}$, menjadi solusi sistem persamaan linear fuzzy $\mathrm{A} \widetilde{U}=\tilde{V}$ jika dan hanya jika entri-entri matriks $B^{-1}$ non-negatif. (Noranita,2008)

Untuk membuktikan bahwa vektor $\widetilde{U}$ yang bersesuaian dengan $U^{*}$ merupakan solusi dari sistem persamaan linear fuzzy, akan dicari $B^{-1}$ dari masing-masing contoh, berdasarkan syarat perlu dan cukup pada teorema 3 .

Contoh 4. :Misalkan diketahui sistem persamaan linear seperti di contoh 1 sehingga

$$
B=\left[\begin{array}{llllll}
1 & 0 & 2 & 0 & 0 & 0 \\
0 & 4 & 6 & 3 & 0 & 0 \\
0 & 0 & 3 & 1 & 2 & 0 \\
0 & 0 & 0 & 1 & 0 & 2 \\
3 & 0 & 0 & 0 & 4 & 6 \\
1 & 2 & 0 & 0 & 0 & 3
\end{array}\right]
$$

dan didapat matriks $B^{-1}=\frac{1}{\operatorname{det}(B)} \operatorname{Adj}(B)$ sebagai berikut : 


$$
B^{-1}=\left[\begin{array}{cccccc}
0.2727 & 0.4545 & -1.0909 & -0.2727 & 0.5455 & -0.9091 \\
-0.3409 & 0.1818 & -0.1364 & -0.4091 & 0.0682 & 0.1364 \\
0.3636 & -0.2273 & 0.5455 & 0.1364 & -0.2727 & 0.4545 \\
-0.2727 & 0.5455 & -0.9091 & 0.2727 & 0.4545 & -1.0909 \\
-0.4091 & 0.0682 & 0.1364 & -0.3409 & 0.1818 & -0.1364 \\
0.1364 & -0.2727 & 0.4545 & 0.3636 & -0.2273 & 0.5455
\end{array}\right]
$$

Terlihat bahwa $B^{-1}$ memiliki entri-entri yang bernilai tidak non-negatif, sehingga tidak memenuhi teorema 3 . Jadi vektor $\widetilde{U}$ yang bersesuaian dengan $U^{*}$ bukan merupakan solusi dari sistem persamaan linear fuzzy pada contoh 1.

Contoh 5. :Misalkan diketahui sistem persamaan linear seperti di contoh 2 sehingga

$$
B=\left[\begin{array}{llll}
0 & 0 & 4 & 0 \\
0 & 0 & 0 & 1 \\
4 & 0 & 0 & 0 \\
0 & 1 & 0 & 0
\end{array}\right] \text { dan didapat matriks } B^{-1}=\frac{1}{\operatorname{det}(B)} \operatorname{Adj}(B)=\left[\begin{array}{cccc}
0 & 0 & 0,25 & 0 \\
0 & 0 & 0 & 1 \\
0,25 & 0 & 0 & 0 \\
0 & 1 & 0 & 0
\end{array}\right]
$$

Terlihat bahwa entri-entri dari $B^{-1}$ non-negatif, sehingga memenuhi teorema 3. Jadi vektor $\widetilde{U}$ yang bersesuaian dengan $U^{*}$ merupakan sistem persamaan linear fuzzy pada contoh 2.

Adapun Algoritma Solusi Sistem Persamaan Linear Fuzzy sebagai berikut :

Diberikan sistem persamaan linear fuzzy .

Langkah 1 : Sistem persamaan linear fuzzy diubah dalam bentuk matriks $\mathrm{A} \widetilde{U}=\tilde{V}$ dengan $\mathrm{A}=\left[a_{i j}\right], \widetilde{U}=\left[\tilde{u}_{j}\right], \widetilde{V}=\left[\tilde{v}_{i}\right]$ untuk $i, j=1,2, \ldots, n$.

Langkah 2 : Mentransformasikan matriks A $\widetilde{U}=\tilde{V}$ ke bentuk persamaan $B U^{*}=V^{*}$

Langkah 3 : Menghitung determinan matriks $B$.

Langkah 4 : Mencari invers matriks $B$.

Langkah 5 : Menyelesaikan sistem persamaan $B U^{*}=V^{*}$.

Langkah 6 : Menampilkan hasil 
Dari uraian di atas dapat digambarkan flowchart atau diagram alur dari algoritma solusi sistem persamaan linear fuzzy sebagai berikut :

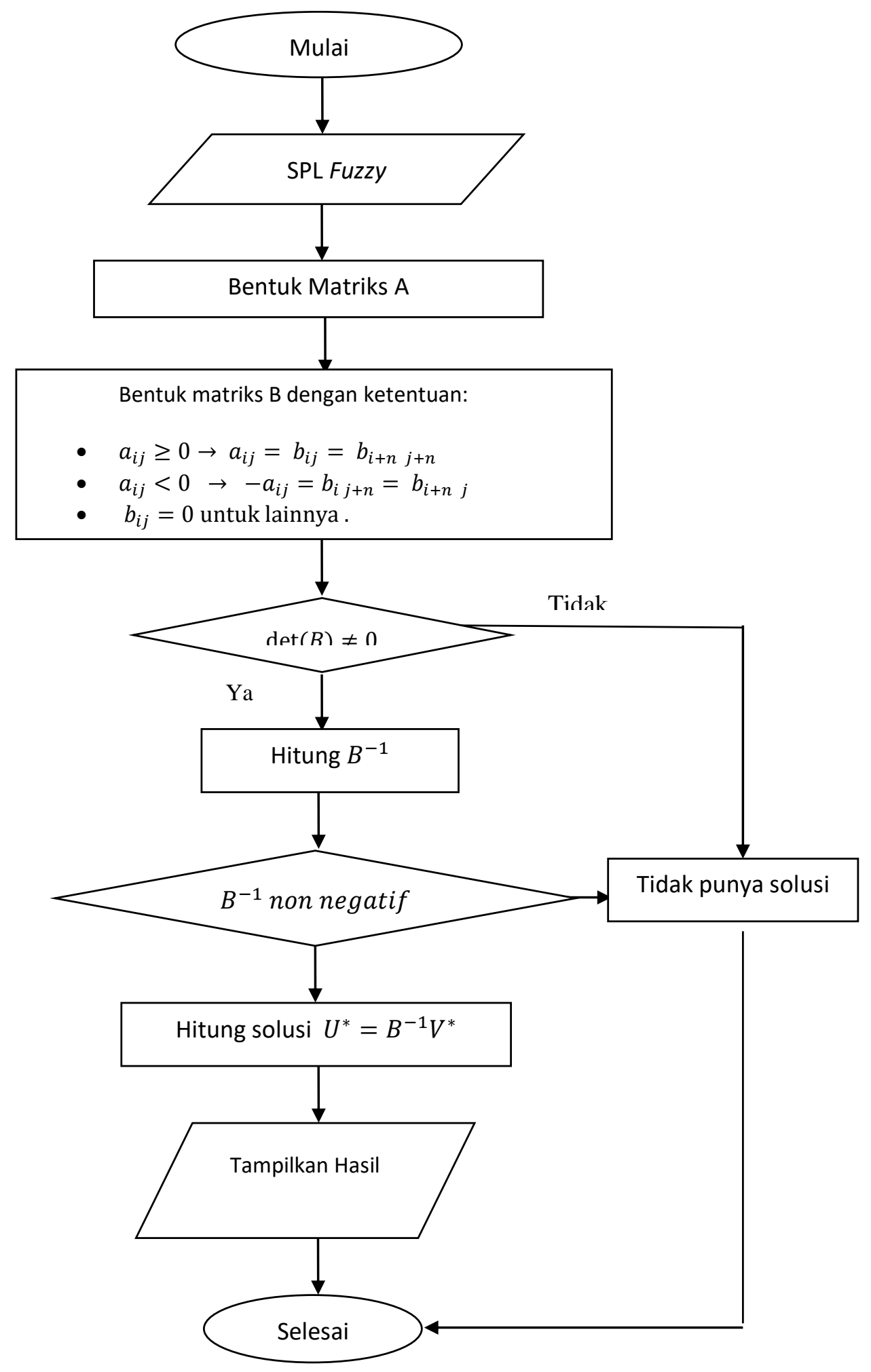

Gambar 1. Flowchart Solusi Sistem Persamaan Linear Fuzzy 


\section{Kesimpulan}

Penyelesaian sistem persamaan linear fuzzy dapat dilakukan dengan mentransformasikan sistem persamaan linear fuzzy $A \widetilde{U}=\widetilde{V}$ ke dalam sistem persamaan linear non-fuzzy $B U^{*}=V^{*}$, selanjutnya dicari $U^{*}$ yang merupakan solusi dari sistem persamaan $B U^{*}=V^{*}$. Vektor $\widetilde{U}$ yang dibentuk dari $U^{*}$ tidak secara langsung menjadi solusi dari sistem persamaan linear fuzzy $A \widetilde{U}=\widetilde{V}$. Syarat perlu dan cukup agar vektor $\widetilde{U}$ yang bersesuaian dengan $U^{*}$ merupakan solusi dari sistem persamaan linear fuzzy $A \widetilde{U}=\tilde{V}$, adalah $B^{-1}$ harus non-negatif. Algoritma yang dibangun untuk mencari solusi sistem persamaan linear fuzzy menggunakan pemograman Matlab akan lebih memudahkan dalam mencari solusi dari sistem persamaan linear fuzzy.

\section{Daftar Pustaka}

Allahviranloo, Tofigh, dkk. 2008. Application \& Applied Mathematics. Signed Decomposition Of Fully Fuzzy Linear Systems, Vol.3, No.1,

Anton, Howard. 1987. Aljabar Linear Elementer, (Edisi Kelima). Jakarta: Erlangga.

Arhami, M, dkk. 2005. Pemrograman Matlab. Yogyakarta: Andi.

Lipschutz,Seymour \& Lipson, Marc.2006. Schaum's Outlines Teori dan Soal Aljabar Linear, (Edisi Ketiga). Jakarta: Erlangga.

Noranita, Beta. 2008. Jurnal Elektronik Undip. Sistem Persamaan Linear Fuzzy. Semarang: Universitas Diponegoro.

Purcell, Varberg, Ridgon. 2003. Kalkulus, (Edisi Kedelapan). Jakarta: Erlangga. 